\title{
Knowledge and Awareness towards Emergency Management of Dental Trauma among the Teachers in Primary Schools in Syria: A Cross-Sectional Study
}

Jawdat M. Ataya ( $\sim$ dr.jawdat.ataya@gmail.com )

\section{Research note}

Keywords: Dental Trauma, Evaluation, Teachers, Knowledge, Children, Damascus, Syria

Posted Date: January 24th, 2022

DOI: https://doi.org/10.21203/rs.3.rs-1288415/v1

License: (c) (i) This work is licensed under a Creative Commons Attribution 4.0 International License.

Read Full License 


\section{Abstract \\ Objective}

The study aimed to assess teachers' knowledge in primary schools about the emergency management of dental trauma.

\section{Material and methods}

A cross-sectional study. A total of 560 teachers from different 28 primary schools in Damascus, Syria, participated in this study. The scale was adopted, where (1 mark) was given for correct answer, (0 marks) for answer I do not know, and (-1 mark) for wrong answer. Then, three levels of knowledge were considered. The Weak level was taken when the sum is less than one mark, the Intermediate level was taken when the sum is between two and four marks and finally and the Good level was taken when the sum is between 5 and 7 .

\section{Results}

404 teachers (72.2\%) were in the Weak Level, 139 teachers (24.8\%) were in the Intermediate Level, 17 teachers (3\%) were in the Good Level. There is no link between gender, age, years of teaching, type of school and having medical or dental first aid with knowledge levels.

\section{Conclusion}

Primary school teachers' knowledge about dental trauma within Damascus is deficient. This study highlighted the reality of knowledge of teachers in schools and will benefit decision-makers to design an educational course for dental trauma.

\section{Introduction}

Dental Trauma is one of the most critical health problems in childhood that cause pain, distress, and dysfunction that accompanies injuries (1). Schools and homes are the most common places for hosting dental trauma injuries $(2,3)$. School teachers are likely to be the first to see a child immediately after an injury, and their sound knowledge about managing traumatic tooth avulsion is essential for effective dental treatment $(1,4)$. Falls, sports, collisions, physical leisure activities, being struck by an object and traffic accidents are the commonly listed causes of traumatic dental injuries $(5,6)$. Andreasen et al. $(7)$ have found that the most traumatic injuries of permanent teeth occur in the age between 9-12 years. The knowledge of dental trauma management is of critical importance to decrease the consequences and improve the prognosis of dental trauma $(1,8)$. The prognosis quite often depends on the child's parents and school teachers present at the accident site prior to referral to a dentist, who has a minor role if the 
optimal urgent care were not initiated in the location of the injury $(9,10)$. Therefore, this study aimed to assess teachers' knowledge in primary schools about the emergency management of dental trauma.

\section{Material \& Methods}

This study has a cross-sectional design. It was undertaken to assess the knowledge of teachers in public and private primary schools in Damascus in May 2021.

A total of 560 teachers from 28 primary schools were recruited. A self-administered anonymous, structured questionnaire was developed and distributed to teachers.

It contained 14 questions. The first seven questions included demographic information (gender, age, years of teaching school type and previous knowledge about dental injuries)-other questions designed to assess knowledge about dental trauma.

A pilot study was conducted and distributed to 68 teachers in five different schools, which have been selected randomly. The questionnaire was amended by deleting some of the questions following the pilot study results. Based on this pilot study, the sample size calculated for the study was 482 teachers who were considered sufficient with $90 \%$ power with a two-sided alpha level of $5 \%$.

The data entry and analysis were performed using Statistical Package for Social Sciences software package (SPSS Inc., Chicago, IL, USA) version 23. The survey was tested for reliability by using Cronbach's alpha test. Internal consistency of (0.702) was reported. Chi-square test was used to find out the association of demographic variables with the level of knowledge regarding first aid, and $\mathrm{P}<0.05$ was considered statistically significant.

\section{Results}

A total of 572 filled questionnaires, giving a response rate of $90.6 \%$. After excluding questionnaires with missing entries in the first section (demographics and background information), there were 560 for analysis. The statistics of the respondents' background information is shown in Table 1. 
Table 1

Demographics and characteristics of respondents $(n=560)$.

\begin{tabular}{|ll|}
\hline Demographics/characteristics & No. (\%) of respondents \\
\hline 1. Gander & $70(12.5)$ \\
\hline a. Male & $490(87.5)$ \\
\hline b. Female & \\
\hline 2. Age Group (years) & $27(4.8)$ \\
\hline a. $\leq 20$ & $184(32.9)$ \\
\hline b. $21-30$ & $208(37.1)$ \\
\hline c. $31-40$ & $124(22.2)$ \\
\hline d. $41-50$ & $14(2.5)$ \\
\hline e. $51-60$ & $3(0.5)$ \\
\hline f. $\geq 61$ & \\
\hline 3. Years of teaching & $273(48.8)$ \\
\hline a. $1-10$ & $179(32.0)$ \\
\hline b. $11-20$ & $85(15.1)$ \\
\hline c. $21-30$ & $23(4.1)$ \\
\hline d. $\geq 31$ & $404(72.1)$ \\
\hline 4. School type & $156(27.9)$ \\
\hline a. Public schools & \\
\hline b. Private schools & \\
\hline
\end{tabular}

The results were $87.5 \%$ of female and $37.1 \%$ males aged between 31 and 40 years. Moreover, $19.5 \%$ (109) had received previous medical first-aid training, but only $3.8 \%$ (21) had received previous dental first-aid training, and only $28.8 \%$ (161) had read or heard about dental injury information besides that from first-aid training.

The distribution of responses to the questions is shown in Table 2. The correct answer(s) for each question were indicated. The majority of teachers answered the questions incorrectly. Only $52.4 \%$ (294) of the respondents correctly identified the appropriate place to treat a dental injury, though $72.0 \%$ (403 teachers) knew the suitable time for treatment. Only $31.4 \%$ (176) of the respondents possessed how to manage fractured teeth correctly. $15.2 \%$ (85) of the respondents exhibited the capability to manage displaced teeth, whereas $75.2 \%$ (421 teachers) answered correctly that avulsed deciduous teeth should not be replanted in the original position. However, a comparatively more notable proportion, $48.5 \%$ (272 
teachers), know that permanent teeth should be replanted. Moreover, only $13.6 \%$ (66) of the respondents determined correctly at least one of the appropriate mediums for storing an avulsed tooth. 
Table 2

Displays the number and the proportion of each choice and selection for each question in the second section of the questionnaire.

\section{Questions to assess their knowledge}

No. (\%) of

respondents

\section{The best for treatment:}

a. In the nearest hospital.

$119) 21.3($

b. Go to the nearest private doctor.

$35(6.3)$

c. Go to a dentist. *

294 (52.4)

d. Treat it by self.

16 )2.9)

e. Do not know.

$15(2.7)$

More than one answer.

$81(14.4)$

\section{Time for treatment:}

a. Immediately. (8)*

403 (72.0)

b. Within 4 hours.

89 (15.9)

c. Within 24 hours.

$36(6.4)$

d. Within 48 hours.

4 (0.7)

e. Do not go at all.

$3(0.5)$

f. Do not know.

$25(4.5)$

10. Immediate management of fractured teeth:

a. Ignore it.

b. Try to find the fractured piece, wrap it with gauze or tissue and bring it for examination and treatment.

c. Put it in liquid and bring it for examination and treatment $(8,17)^{\star}$.

d. Do not know.

$109(19.5)$

11. Immediate management of displaced teeth:

a. Do not touch, let it remains in its new position.

b. Try to put back to the original position.

101 (18.0)

c. Ask the patient to carefully clench one's teeth if it is possible $(12,17)$ *

d. Do not know

126 (22.5)

12. Should knocked-out baby teeth be put back to their original position? 


\section{Questions to assess their knowledge}

No. (\%) of

respondents

a. Yes.

$43(7.7)$

b. No. $(9,17)$ *

$421(75.2)$

c. Do not know

$96(17.1)$

13. Should knocked-out permanent teeth be put back to their original position?

a. Yes. $(8,9,17)$ *

$272(48.5)$

b. No.

$105(18.8)$

c. Do not know

$183(32.7)$

\section{The best liquid for storing knocked-out teeth:}

Has been selected one of the wrong answers.

$327(58.4)$

c. Physiological saline. $(8,9,17)$ *

$39(7.0)$

d. Put it in milk. $(8,9,17)$ *

$15(2.7)$

e. Put it in patient's saliva. $(8,9,17)$ *

$22(3.9)$

j. Do not know.

$155(27.7)$

c and d. Put it in milk and Patient's saliva. $(8,9,17)]$ *

$2(0.3)$

* Correct answer for the question

The following scale was adopted, where ( 1 mark) was given for each correct answer, ( 0 marks) for each answer I do not know, and (-1 mark) for each wrong answer, because the current information is an essential and integrated information and any error in it means that it is hurting the patient rather than helping him. The sum is between -7 for those whose answers were all wrong and 7 for those whose answers were all correct.

Then, three levels of knowledge were considered. The weak level was taken when the sum was less than one mark, the Intermediate level was taken when the sum was between two and four marks, and finally, the Good level was taken when the sum was between 5 and 7. The results were as follows; Weak level 404 (72.2\%), Intermediate level: 139 (24.8\%) and the Good level: 17 (3\%). Total scores are shown in Table 3. The mean and median total scores were positive, with values of 0.4982 and 1 , respectively, which showed that the level of knowledge about dental injury treatment among teachers was insufficient. 
Table 3

Summary statistics of the total score of the

respondents

\begin{tabular}{|ll|}
\hline Statistics & Data \\
\hline Mean & .4982 \\
\hline Median & 1.0000 \\
\hline Mode & 1.00 \\
\hline Std. Deviation & 2.11815 \\
\hline Minimum & -5.00 \\
\hline Maximum & 7.00 \\
\hline Sum & 279.00 \\
\hline
\end{tabular}

The demographic background (gender, age, number of years of teaching, and school type) did not affect the knowledge of dental injury management. Also, receiving medical and dental first-aid training and reading or hearing about dental injury information did not affect the total score, and Table 4 shows the $p$ value for those independent variables and the test used.

Table 4

Relationship between total score and the independent variables and the type of used test.

\begin{tabular}{|lll|}
\hline The Factor & Test's type & $\mathrm{P}$ value \\
\hline 1.Gender & Chi-Square & $\mathrm{P}=0.474$ \\
\hline 2. Age & ANOVA & $\mathrm{P}=0.476$ \\
\hline 3. Years of teaching & ANOVA & $\mathrm{P}=0.247$ \\
\hline 4. School type & Chi-Square & $\mathrm{P}=0.628$ \\
\hline 5. Received Medical first-aid training & Chi-Square & $\mathrm{P}=0.807$ \\
\hline 6. Received Dental first-aid training & Chi-Square & $\mathrm{P}=0.35$ \\
\hline 7. Read or heard dental injury information about dental trauma & Chi-Square & $\mathrm{P}=0.641$ \\
\hline
\end{tabular}

\section{Discussion}

The most significant age exposed to traumatic dental injuries is between 9 and 12 years $(1,7)$. Teachers are closer to the children of those ages, so processing initial aid of the trauma improves the prognosis of the injury, and because of this, the primary schools were chosen $(11,12)$. The names of public and private primary schools in Damascus were obtained from the Syrian Ministry of Education. Some schools were 
chosen randomly according to the socio-economic status of the area of schools. The best method was willing to respond to the self-administered anonymous, structured questionnaire.

The concentration was on the effects of gender, age, years of teaching, school type, received medical and dental first-aid training and if they read or heard about dental injury information about dental trauma with their knowledge.

Many similar studies published in many countries have found, including China(13), Jordan (14), Brazil (15) and some other countries (4), and the results were considered similar to our study, which showed a vast lack of knowledge about how to manage dental trauma.

The ratio of teachers who received medical first-aid training was only 19.5\% (109 teachers). Compared with the studies conducted in China (13) and Jordan (14), their ratios were $50 \%$ and 46 , respectively. That indicates a lack of guidance teachers in Damascus about a course in the medical first-aid training.

In this study, the total of teachers who received dental first-aid training was only 3.8\% (21) which was similar to results obtained from other studies $(13,14)$. That indicated the presence of a significant lack of awareness of the necessity of dental trauma courses and perhaps because of a lack of its presence. There are several attempts to raise dental trauma awareness in primary schools in Syria, aiming to promote and spread awareness of dental trauma for students and not for teachers (16).

When comparing the changes in the level of knowledge with if they received medical and dental first-aid training, it did not show any significant change in the level of knowledge.

This study revealed that those teachers who have equipped themselves with some information about dental trauma were only $161(8.28 \%)$, and there is no significant association with the level of knowledge.

Usually, the dentist is considered responsible for handling dental trauma cases. When the question which referred to the best place to receive appropriate treatment was asked, the percentage of teachers who selected option (c. At the nearest dentist) was 52.5\% (294). This percentage has agreed with several previous studies $(4,13-15)$.

Preferably, traumatic dental injuries treat immediately to improve the prognosis $(1,5)$, so when we asked about the best time for treatment, the high percentage, $72 \%$ (403 teachers), was to the option (a. immediately), and this is a good percentage. It is very close to the ratio of choosing the correct answer at Young, $74.7 \%$ (13).

Nevertheless, when exposed to the fractured tooth, the appropriate measure is (c. Put it in a liquid and bring it for examination and treatment.) $(5,17)$, and the percentage of those who chose it was $31.4 \%$ (176). The option, which has obtained the highest percentage, was (b. Try to find the fractured piece, wrap it with gauze or tissue and bring it for examination and treatment) and it was $37.9 \%$ (212). This measure is wrong as it inevitably must remain wet $(5,17)$. 
Regarding how appropriate dental management is when changing the place of tooth and localization, the correct answer (b. Try to put back to the original position) was 18\% (101), and it was a low ratio. Nonetheless, the answer with the highest percentage was (a. Do not touch, let it remain in its new position), by $44.3 \%$ (248); it is the wrong choice.

Temporary teeth cannot be planted if deposed $(5,17)$, so when we asked the question about the possibility to replant the temporary tooth after deposing it, the highest percentage of answers was (b. No) by $75.2 \%$ (421); this is correct, and this is consistent with previous studies (13-15).

However, the permanent teeth can be replanted after deposing them $(5,17)$. The ratio of the option (a. Yes) was $48.6 \%$ (272 teachers); this differs from other studies where the percentage of the correct answer were $16.2 \%(13)$ and $22.7 \%(15)$.

The preferred liquid for putting the deposed tooth in it is HBSS, a commonly used fluid in stadiums and the preferred liquid then milk and saline; they save the tooth for a while two hours and then saliva, where he saves the age for half an hour $(5,17)$. The last question was about the importance of placing the tooth in the fluid. There were three right choices are (c. put the tooth in saline), and its percentage was 7\% (39 teachers), and (d. Put the tooth in milk), its percentage was 2.7\% (15 teachers), and (e. Puts the tooth in the patient's saliva), his choice rate is $3.9 \%$. (22 teachers), while those who chose both options (c and d) were $0.4 \%$ ( 2 teachers), and that is not similar to studies $(1,8,13,14)$.

The results of this study showed a low knowledge level in the dental trauma management in Damascus, perhaps due to a low number of teachers who have done the dental first-aid due to the non-proliferation of such medical courses or because of the absence of this emergency dental information within the paramedics' general courses and lack of attention to matters of dental trauma in their programs.

\section{Conclusion}

Primary school teachers' knowledge about dental trauma within Damascus is deficient. This study highlighted on the reality of knowledge of teachers in primary schools and will benefit decision-makers to design an educational course for dental trauma in Syria.

\section{Limitations}

The questions focused mainly on the basic information in the management of dental trauma, and we did not address the secondary information, which is less important.

\section{Declarations}

Acknowledgements

Not applicable. 


\section{Authors' contributions}

$\mathrm{JA}$ and $\mathrm{OH}$ contributed to conception and design of the study, collecting and data analysis and interpretation, and drafting the manuscript. $\mathrm{OH}, \mathrm{MD}$ and JA2 contributed to writing and revision the final draft . All authors approved the final version of the article. There has been no funding for this study.

\section{Availability of supporting data}

All the necessary data are presented herewith. However if needed, raw data on excel format can be availed on reasonable request from the corresponding author.

\section{Ethics approval and consent to participate}

All patients will be provided written informed consent and approval has been received from the Ethics Committee of Faculty of Dentistry of Damascus University (45/224, 24-2- 2021). Personal information about patients will be preserved in a database to protect patients' security.

\section{Consent for publication}

Not applicable.

\section{Competing interests}

The authors declare that they have no competing interests.

\section{References}

1. Fouad AF, Abbott P V., Tsilingaridis G, Cohenca N, Lauridsen E, Bourguignon C, et al. International Association of Dental Traumatology guidelines for the management of traumatic dental injuries: 2 . Avulsion of permanent teeth. Dent Traumatol. 2020;36(4):331-42.

2. Bendo CB, Paiva SM, Oliveira AC, Goursand D, Torres CS, Pordeus IA, et al. Prevalence and associated factors of traumatic dental injuries in Brazilian schoolchildren. J Public Health Dent. 2010;

3. U. G. Aetiology and risk factors related to traumatic dental injuries - A review of the literature. Dent Traumatol. 2009;

4. Hashim R. Dental trauma management awareness among primary school teachers in the Emirate of Ajman, United Arab Emirates. Eur J Paediatr Dent. 2011 Jun;12(2):99-102.

5. Andreasen Andreasen, F. M., Andersson, Lars., JO. Textbook and Color Atlas of Traumatic Injuries to the Teeth. Hoboken: Wiley; 2013.

6. Bastone EB, Freer TJ, McNamara JR. Epidemiology of dental trauma: A review of the literature. Aust Dent J. 2000;45(1):2-9. 
7. Andreasen FM, Andreasen JO. Diagnosis of luxation injuries: the importance of standardized clinical, radiographic and photographic techniques in clinical investigations. Endod Dent Traumatol. 1985 Oct;1(5):160-9.

8. Cagetti MG, Marcoli PA, Berengo M, Cascone P, Cordone L, Defabianis P, et al. Italian guidelines for the prevention and management of dental trauma in children. Ital J Pediatr. 2019;45(1):1-14.

9. Caglar D, Kwun R, Douglass ABFAAFP, Douglass D.D.S. JBDS, Herman F.A.C.E.P. MIFAAP. Initial Assessment and Management of Pediatric Dental Emergencies. Pediatr Emerg Med Pract. 2010;

10. O'neill G. Dental trauma: Trauma protocol for schools. Br Dent J [Internet]. 2018;225(5):376. Available from: http://dx.doi.org/10.1038/sj.bdj.2018.765

11. Feiglin B. Dental pulp response to traumatic injuries-a retrospective analysis with case reports. Endod Dent Traumatol. 1996 Feb;12(1):1-8.

12. Khan L. Dental Care and Trauma Management in Children and Adolescents. Pediatr Ann. 2019 Jan;48(1):e3-8.

13. Young C, Wong KY, Cheung LK. Emergency management of dental trauma: knowledge of Hong Kong primary and secondary school teachers. Hong Kong Med $\mathrm{J}=$ Xianggang yi xue za zhi. 2012 Oct;18(5):362-70.

14. Al-Jundi SH, Al-Waeili H, Khairalah K. Knowledge and attitude of Jordanian school health teachers with regards to emergency management of dental trauma. Dent Traumatol. 2005;

15. Lima DC De, Saliba SA, Adas C, Garbin S, Araujo L. Knowledge and Attitude of Brazilian Elementary School Teachers Towards Dental Trauma. 2021;1-11.

16. Zaher N Al, Dashash M. An educational intervention for improving knowledge of Syrian school children about avulsion using the " save your tooth " poster. BMC Oral Health [Internet]. 2021;1-7. Available from: https://doi.org/10.1186/s12903-020-01380-4

17. Flores MT, Andersson L, Andreasen JO, Bakland LK, Malmgren B, Barnett F, et al. Guidelines for the management of traumatic dental injuries. II. Avulsion of permanent teeth. Dent Traumatol Off Publ Int Assoc Dent Traumatol. 2007 Jun;23(3):130-6. 